\title{
Research and Practice on Bilingual Teaching of Data Mining Course for Statistics Postgraduates
}

\author{
Xing $\mathrm{Xu}^{1, \mathrm{a}^{*}}$, Bingxiang $\mathrm{Liu}^{1}$ and $\mathrm{Na} \mathrm{Hu}{ }^{2}$ \\ ${ }^{1}$ School of Foreign, Jingdezhen Ceramic Institute, Jingdezhen 333403, China; \\ ${ }^{2}$ School of Information, Jingdezhen Ceramic Institute, Jingdezhen 333403, China \\ awhuxx84@aliyun.com \\ * The corresponding author
}

Keywords: Bilingual teaching; Data mining; Teaching methods; Research-oriented teaching

\begin{abstract}
The data mining course is an important course of postgraduates of statistics and computer science and technology majors in Jingdezhen Ceramic Institute. In order to improve the postgraduates' ability of learning the latest expertise in the field of data mining and tracking the frontiers of discipline, we choose the classic English textbooks, write English courseware, publish English scientific papers, let them simulate and participate in international academic conferences and use other bilingual Teaching practice modes.
\end{abstract}

\section{Introduction}

Ranked as the highest level in the structure of education, postgraduate education has been developing with diversification and internationalization as its common trend, and the teaching of postgraduate courses had been designed for professional skills and ability of international communication. With the rapid development of global economy, there has been a growing need for "bilingual professionals" who are proficient in one or more foreign language [1] [2]. Either of the national level or the university level, the a joint training does provide opportunities for students to study in some famous foreign universities as exchange students and to study abroad with scholarships, but only a small portion of postgraduate students are lucky enough to get this kind of opportunity, and the rest students have to seek for higher education to achieve the internationalization of education. The purpose of bilingual teaching and reference to the original foreign teaching materials is to make up for this shortcoming. In the way of bilingual teaching, postgraduate education is supposed to improve students' ability of mastering the latest professional knowledge and tracking the forefront of scientific and technological information [3]. Therefore, the bilingual teaching for postgraduate education in colleges and universities to is of great significance.

"Data Mining", traditionally taken as the professional course for statistics and computer science majors, the postgraduate students are required to master both the basic theory and application technology dual nature. On the one hand this course can be directly used to solve the business intelligence, fault diagnosis and other areas of scientific decision-making; On the other hand, it is the theoretical basis of many other disciplines, such as the discovery of various causes of medical research [4]. It plays an important role in cultivating students' ability to analyze and to solve the intelligent analysis problem of large-scale data. in the current "data explosion" era[5] [6], the quality of technical personnel training depends on the curriculum construction, the teaching reform and the teaching efficiency. "Data mining", whose content is novel and the discipline is developing rapidly, is a new discipline developed with the digital age. This course involves the integration of multidisciplinary technology, many related courses can be listed as follows: database technology, statistics, machine learning, pattern recognition, high performance computing, Network, support vector machine, information retrieval, data visualization, image and signal processing, spatial data analysis, and so on. With the increasing development in the data mining field, this course could be better improved by the way of bilingual teaching. The bilingual teaching approach not only strengthens the postgraduate students' ability to 
master the professional vocabulary and construct the professional knowledge framework but also keeps them abreast of the forefront of the data field and always be ready to update their professional knowledge system [7] [8].

\section{Bilingual Teaching Approach}

Selection English Textbook and Supplementary Learning Materials. The selection of high-quality bilingual teaching materials in the bilingual teaching comes in the first place, it provides the best language samples and a systematic, targeted language practice materials for classroom teaching, and it dominates the in-class teaching and learning to a large extent, thus, the teaching contents and approach is bound to affect the student's learning behavior patterns and learning outcomes. Therefore, the selection of high-quality bilingual teaching materials is the basis for completing postgraduate bilingual teaching. Many English original textbooks are classic, and do contain a lot of knowledge and information. However, taking the students' knowledge and foreign language proficiency into consideration, these foreign teaching materials in the professional knowledge maybe beyond their ability to master. Therefore, it is of great need to prepare some auxiliary reference materials for these original textbooks , and the preparation of English teaching course helps the teacher to comb the key point and to grasp the main ideas of those teaching materials. At the same time, students are motivated to seize the focus of learning and review of information based on auxiliary information which is difficult to facilitate teaching and learning. And it is also likely to facilitate students to control their learning by choosing a Chinese translation of the original English textbooks. Inspired by this approach, the author selected the textbook "Data Mining: Concepts, Models, Methods and Algorithms" (second edition), written by Mehmed Kantardzic, published by Tsinghua University Press. The original textbook published is shown as Fig. 1.



Figure 1. The textbook of data mining 
English Papers on Research. The writing of English scientific papers is a necessary skill for international academic exchange, by which the participants can comprehend other scholars' the research contents and methods through reading their English papers. By writing and publishing English scientific papers, we can show our research results to scholars in related fields. With in-class or extracurricular guidance, the students in this paper are trained to publish English science and technology papers on decision-making trees, genetic algorithms, particle swarm optimization algorithms and neural networks. In the process of writing papers, the students try to get access to domestic and foreign literature, in fact, this is a process of heading into the forefront of data mining research dynamic digestion and absorption. After the writing is completed, students are expected to explain their own papers in English in class, this is also a process for students to digest and absorb what they have learned after the sublimation. Only can the students fully understand the basis of teaching when they are allowed to figure out the contents by themselves. The paper about data mining field written by the postgraduate of Grade 2014 is submitted online and shown as Fig. 2.

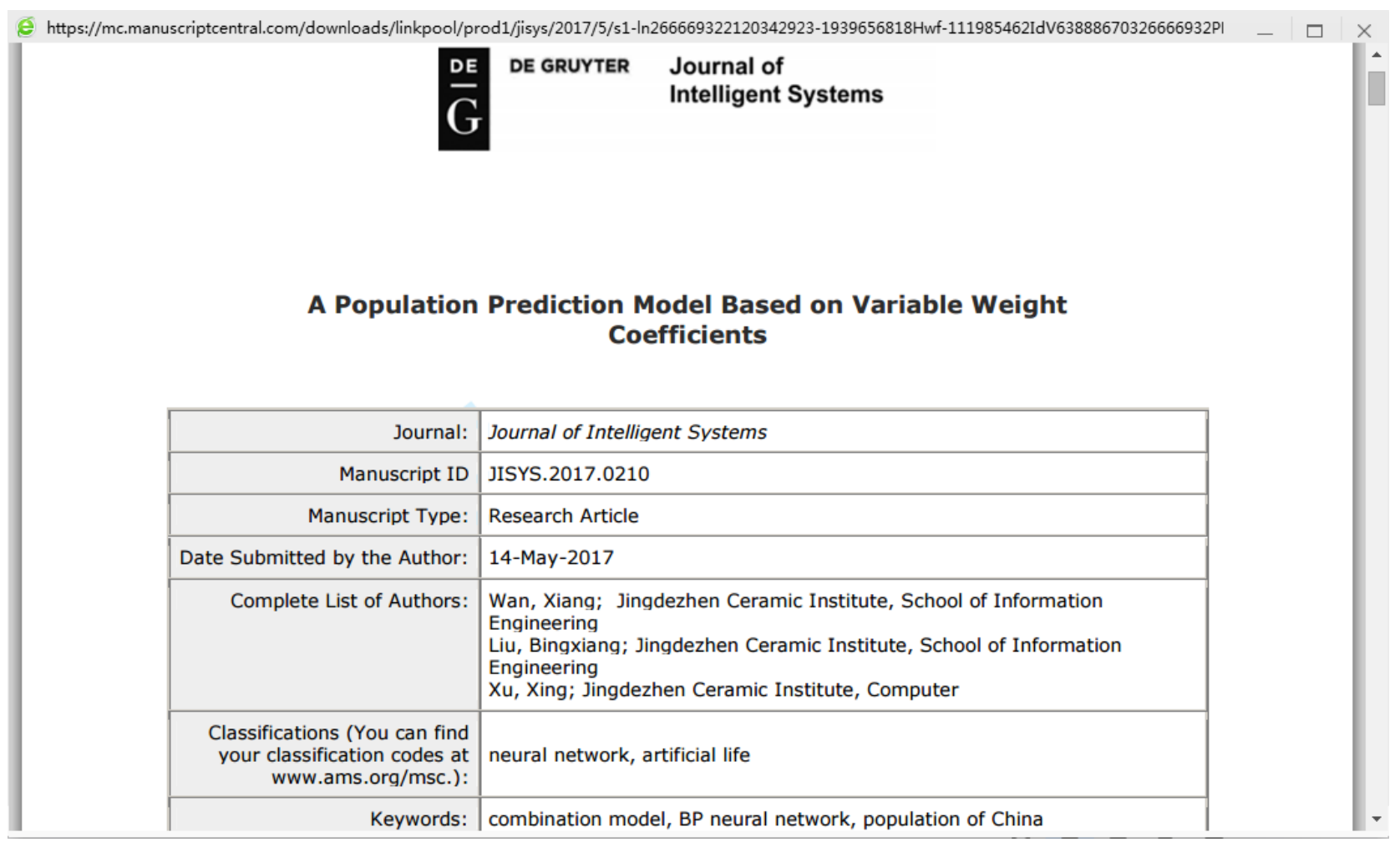

Figure 2. The paper written and submitted by the postgraduate of Grade 2014

Participation in International Academic Conferences and Forums. Attended by the staff at home and abroad experts, scholars and teachers and students, the international academic conference, which is hopefully to broaden the students' academic horizon and to raise their awareness of forefront in their field, is a very good platform for academic exchange. By attending international conferences, students have the opportunity to communicate face-to-face with experts and scholars, especially foreign experts and scholars in English. First of all, the in-class simulation of an international academic conference on the data mining arranged for students to do in English neural network, large data, in-depth study and other aspects of academic reports, and the students were asked to communicate in English during the whole process. In addition, students also participated in the international conferences and forums held in the school, for example, 2015 ISCAEE International Education Exchange Society, 2015 China (Jingdezhen) High-tech Ceramics International Forum and the 9th Asian Ceramic Materials Seminar, "Maritime Silk Road - Ceramic Road "Jingdezhen ceramics and " the belt and the road" strategic international academic seminar. Finally, under the prerequisite of the school or mentor funding, students 
are encouraged to study abroad, to study outside the province, and to participate in foreign international academic conferences and forums.

Other Forms of Practice. The bilingual teaching approach, the basic form of in-class teaching, motivates postgraduate students to master the basic master the basic English vocabulary and professional terms of expression and at the same time lays a a better professional English foundation for them. In addition, this paper tried to highlight the increasing need to expand the content, to form a bilingual teaching practice model with variety, and to increase the students' enthusiasm to learn. For example, inviting domestic and foreign scholars to do academic lectures and reports in English, writing courses in English, watching foreign high level experts and scholars of academic lectures video. The author of the United States during the visit to the results of "genetic algorithm based on real-time strategy game control and optimization" for all the Graduate School of Information Engineering to do an English academic lectures.

\section{Summary}

Through adopting bilingual teaching in the data mining course for grade 2014 and grade 2015 of statistics postgraduates of school of information engineering of Jingdezhen Ceramic Institute, we explore a variety of bilingual teaching practice models, such as, selecting the classic English textbooks, writing the English courseware matched with the textbooks, writing and publishing the English scientific papers, simulating the international conferences in the classroom, participating the international conferences and forums, listening the foreign academic lectures and videos and so on. These methods are useful to broaden their horizons, develop the research ability and improve oral English expression. However, some problems have also been exposed in the course of teaching practice. The oral English expression is not idiomatic and fluent; the tense and structure in the academic papers is not very accurate; the academic reports about statistics and computer are not enough; the opportunity of attending international meetings abroad is rare. We hope that these problems can be solved and improved in the following bilingual teaching process of Data Mining for the Grade 2016 and Grade 2017.

\section{Acknowledgements}

This paper was supported by the Science Foundation of Jiangxi Provincial Department of Education (GJJ14639,GJJ151547), Art sciences planning project of Jiangxi province(YG2016015), Humanities and social science research project of Jiangxi province(SH162002), A Special Fund for Mid-aged and Yong Teachers as Visiting Scholars in Jiangxi General Undergraduate Universities, excellent engineer training program of computer science and technology major of Jiangxi province, postgraduate teaching reform project of Jingdezhen Ceramic Institute -- "bilingual teaching exploration and practice of postgraduate data mining course".

\section{References}

[1] Xilin Xiao, Jian Deng, Lifu Liao et al, Practice and exploration of bilingual teaching of postgraduate courses in local colleges and universitie, higher education in chemical engineering, 1(2014) 27-30.

[2] Chenjun Liu, Exploration and innovation of college postgraduate bilingual teaching model, China Electric Power Education, 23(2010) 106-107.

[3] Information on http://www.being.org.cn/unique/dw2.htm

[4] Information on https://en.wikipedia.org/wiki/Data_mining

[5] Guozhi Long, The status quo of Chinese college bilingual teaching, Reform and opening, 4 (2011) 173-174.

[6] Feng Shi, Several important practice models of bilingual teaching in postgraduate education, The Science Education Article Collects, 5 (2012) 25-26.

[7] Wei Zhao, Zhaotao Lu, Bilingual teaching reform of computer professional courses, Education and Teaching Forum, 26 (2012) 182-183. 
[8] Qing Ye, Changhua Liu, The application of bilingual teaching in the training of computer majors, Science and Technology Information, 2011 (05) 185-185. 